\title{
Lack of effect of preoperative norfloxacin on bacterial contamination of anterior chamber aspirates after cataract surgery
}

\author{
D K Chitkara, T Manners, F Chapman, M G Stoddart, D Hill, D Jenkins
}

\begin{abstract}
Eighty patients undergoing routine standardised extracapsular cataract surgery with lens implantation were divided randomly into two groups in a prospective double blind study comparing effects of preoperative norfloxacin eyedrops with placebo on bacterial contamination of anterior chamber aspirates after surgery. Pathogenic organisms were identified from $19(24 \%)$ of the aspirates. The most commonly isolated organisms were coagulase negative Staphylococcus species. There was no statistical difference between the norfloxacin treated and placebo groups. This study demonstrates that routine use of topical preoperative antibiotics to eliminate the entry of bacteria into the eye during surgery is debatable.
\end{abstract}

(Brf Ophthalmol 1994; 78: 772-774)

Although the incidence of postoperative endophthalmitis has declined sharply over the past 50 years, it remains a devastating complication of cataract surgery. The mechanism of infection in most cases can only be postulated but it seems likely that in the majority of cases the entry of bacteria occurs at the time of surgery.

It is well known that the conjunctiva of patients undergoing cataract surgery is heavily populated with bacteria. Sherwood et $a l^{1}$ and Dickey et $a l^{2}$ have recently shown a $29-43 \%$ bacterial contamination rate of anterior chamber after extracapsular cataract extraction (ECCE) and it is assumed that fluid from the conjunctival sac containing bacteria routinely enters the anterior chamber during cataract surgery. Therefore, while bacteria may enter the eye from numerous sources such as upon the surface of PMMA lenses, surgical instruments, surgeon's skin, or from airborne particles, it seems prudent to attempt to minimise the number of bacteria entering the eye from the conjunctiva and tear film. Meticulous aseptic technique may be the most effective way to prevent postoperative endophthalmitis, although the prophylactic use of topical antibiotics remains controversial. Previous studies by Whitney $e t a l^{3}$ and Apt et $a l^{4}$ have investigated the prophylactic use of preoperative antibiotics on conjunctival flora and these studies perhaps unsurprisingly have failed to demonstrate sterility of conjunctival swabs obtained after antibiotic treatment. This study has been designed to measure quantitatively and compare the effect of preoperative antibiotic application on the contamination rate of the anterior chamber after ECCE with intraocular lens (IOL) implantation.
Materials and methods

Eighty patients undergoing routine ECCE with insertion of IOL were recruited into a prospective double blind carefully controlled study. All patients were fully informed and gave written consent before being entered into this study which met with local hospital ethics committee approval. The exclusion criteria included: (a) history or evidence of previous surgery or penetrating eye injury; (b) local or systemic infection at time of surgery; (c) evidence of posterior capsule rupture during surgery; (d) any additional procedures required during surgery.

Patients were randomised into two groups: group I patients were prescribed norfloxacin eyedrops every 2 hours for at least 6 hours and a maximum of 12 hours preoperatively; group II patients were prescribed normal saline eyedrops every 2 hours.

In theatre a meticulous aseptic preparation was performed on all patients in an identical fashion using $7 \cdot 5 \%$ povidone iodine solution applied to the skin around the eye and conjunctival fornices. The patient's face was then draped with a sterile cloth towel and excess povidone iodine was wiped away with sterile ribbon gauze. The eyelids were opened and clear adhesive steridrape was applied over the lids. Thereafter a standardised ECCE using an envelope technique with posterior chamber lens implantation was performed. In all cases a corneal section was used and all viscoelastic was removed with the anterior chamber being reformed with balanced salt solution before closure of the final corneal suture. After wound closure a sterile 27 gauge cannula attached to a tuberculin syringe was placed in the anterior chamber and $0.2 \mathrm{ml}$ of fluid was aspirated. One hundred milligrams of subconjunctival cefuroxime was injected into the inferior fornix at the conclusion of each operation.

Aspirates were inoculated immediately in equal portions onto a chocolate agar plate and into brain-heart infusion broth. The cultures were sealed in the operating room and transported immediately to the university department of clinical microbiology. Chocolate agar plates were incubated at $37^{\circ} \mathrm{C}$ in air with $5 \%$ carbon dioxide for 5 days and fluid media were incubated at $37^{\circ} \mathrm{C}$ for 48 hours then subcultured onto chocolate agar plates incubated aerobically and anaerobically.

\section{Results}

Of the 80 eyes sampled, we obtained a positive bacterial growth in 19 eyes representing a contamination rate of $24 \%$ (Table 1 ). Of the 19 positive cultures 10 were identified in the 
Table 1 Combined results of growth from anterior chamber aspirate

\begin{tabular}{lll}
\hline Treatment & No growth & $\begin{array}{l}\text { Growth (direct } \\
\text { and broth) }\end{array}$ \\
\hline Norfloxacin & 31 & 10 \\
Placebo & 30 & 9 \\
Total & $61(76 \%)$ & $19(24 \%)$ \\
\hline
\end{tabular}

Table 2 Results of growth in direct and broth cultures from anterior chamber aspirates

\begin{tabular}{llcl}
\hline Treatment & No growth & $\begin{array}{l}\text { Growth on } \\
\text { broth culture }\end{array}$ & $\begin{array}{l}\text { Growth on } \\
\text { direct culture }\end{array}$ \\
\hline Norfloxacin & 31 & 5 & 6 \\
Placebo & 30 & 6 & 3 \\
Total & 61 & 11 & 9 \\
\hline
\end{tabular}

Table 3 Growth of bacterial colonies from direct culture

\begin{tabular}{llll}
\hline $\begin{array}{l}\text { Patient } \\
\text { no }\end{array}$ & Organism & $\begin{array}{l}\text { Colony } \\
\text { forming } \\
\text { units/ml }\end{array}$ & Tor P \\
\hline 16 & Saprophytic Neisseria sp & 10 & $\mathrm{P}$ \\
21 & Coag - ve Staphylococcus & 10 & $\mathrm{~T}$ \\
24 & Coag - ve Staphylococcus & 10 & $\mathrm{~T}$ \\
27 & Micrococcus sp & 10 & $\mathrm{P}$ \\
35 & Bacillus sp & 20 & $\mathrm{~T}$ \\
100 & Coag - ve Staphylococcus & 10 & $\mathrm{P}$ \\
102 & Coag - ve Staphylococcus & 40 & $\mathrm{~T}$ \\
106 & Coag - ve Staphylococcus & 10 & $\mathrm{~T}$ \\
121 & Coag - ve Staphylococcus & 10 & $\mathrm{~T}$ \\
\hline $\mathrm{T}=$ Treatment, $\mathrm{P}=$ Placebo. & &
\end{tabular}

norfloxacin treated group and nine in the placebo group. Ten of the isolates were positive only after enhancement in broth medium and nine were identified from direct culture onto chocolate agar. One aspirate was positive in both broth and chocolate agar medium (Table 2). The most commonly isolated organisms were coagulase negative staphylococci found in 14 of the 19 isolates (74\%). One each of Micrococcus species, Bacillus species, and saprophytic Neisseria species were also isolated. One isolate was a mixed growth of Micrococcus species and coagulase-negative staphylococci.

The use of chocolate agar plates allowed quantification of organisms into colony forming units (CFU). The inoculum dose was found to be small (Table 3). All organisms were found in inoculum sizes of $10 \mathrm{CFU} / \mathrm{ml}$ except two of the isolates, one of which was $20 \mathrm{CFU} / \mathrm{ml}$ and the other $40 \mathrm{CFU} / \mathrm{ml}$. Three of these were from the placebo group and six from the norfloxacin treated group.

\section{Discussion}

Postoperative endophthalmitis remains an often devastating complication of intraocular surgery despite improved methods of prophylaxis and treatment. The reported incidence after modern intraocular surgery averages about $0 \cdot 1 \% .^{56}$ This study confirms that the anterior chamber of patients undergoing extracapsular surgery is often not sterile at the end of the surgical procedure and the contamination rate of $24 \%$ demonstrated is comparable with other studies. ${ }^{12}$ There were no cases of clinical bacterial endophthalmitis despite the noted contamination rate which might be partly due to the small inoculum size $(10-40 \mathrm{CFU} / \mathrm{ml})$. It is notable that in similar studies of anterior chamber contamination no cases of endophthalmitis were identified suggesting that in humans the anterior chamber may be capable of clearing a low inoculum of bacteria. Significantly the aqueous humour of patients undergoing cataract surgery does contain immunoglobulins and complement components. ${ }^{78}$ Subconjunctival antibiotics given at the end of surgery should in theory prevent infection as therapeutic levels are delivered in the anterior chamber. ${ }^{9}$ Studies by Perlman ${ }^{10}$ and Kolker $e t a l^{11}$ indicated the effectiveness of subconjunctival antibiotics but the evidence is not conclusive. In this study subconjunctival cefuroxime was given prophylactically to prevent endophthalmitis. Other factors may also influence progression to endophthalmitis such as integrity of posterior capsule ${ }^{1213}$ and organism virulence. ${ }^{14^{15}}$ The type of intraocular lens used may also be a significant risk factor in the progression or non-progression to endophthalmitis since it has been demonstrated that bacteria adhered preferentially to haptics made of polypropylene compared with PMMA. ${ }^{16}$ Thus, bacteria carried into the eye by irrigation might then adhere preferentially to the haptics and thus attain an increased level of antibiotic resistance as Griffiths and colleagues ${ }^{17}$ have demonstrated. Indeed, Menikoff $e t a l,{ }^{18}$ in a case control study, confirmed a significantly increased risk of endophthalmitis associated with use of a posterior chamber IOL with polypropylene haptic. Other risk factors known to play a role in development of endophthalmitis include amount of instrumentation, manipulation of eye, diabetes, and chronic alcoholism. In this study all operations were performed by two surgeons (DKC and FC) following a standardised operating technique. All intraocular procedures were completed within 25 minutes and any deviations from standard technique resulted in exclusion from the trial.

The organisms isolated in greatest frequency were coagulase negative staphylococci, and in a recent review of 32 cases of endophthalmitis following extracapsular cataract surgery $55 \%$ of the causative organisms were Staphylococcus epidermidis. ${ }^{19}$ Numerous other studies have similarly identified coagulase negative Staphylococcus species as the leading cause of endophthalmitis after cataract surgery. ${ }^{20-22}$ Significantly the organisms isolated in this study are commonly found on ocular adnexae as commensals. ${ }^{23}$ Although previous studies have noted the effect of preoperative antibiotic on conjunctival flora, to our knowledge the effect of preoperative antibiotic on the anterior chamber contamination rate has not been studied previously.

Norfloxacin is a newer fluoroquinolone carboxylic acid active in vitro against a broad array of Gram negative pathogenic bacteria including $P$ aeruginosa, Haemophilus influenzae, Klebsiella species as well as staphylococci. ${ }^{24}$ Although it lacks bactericidal activity against streptococci all remaining potentially dangerous microorganisms are within minimum inhibitory concentration $90\left(\mathrm{MIC}_{90}\right)$ range. Following topical administration it remains in the conjunctival fornix reaching high therapeutic levels. ${ }^{25}$ Owing to low toxicity and spectrum of antibacterial activity it would therefore appear to be an 
excellent antibiotic for prophylactic use in order to eradicate or drastically reduce the bacterial count in the conjunctival fornix before surgery. The antibiotic schedule used in this study was designed not only for its effectiveness but also for its ease of administration by the hospital personnel.

The effect of preoperative norfloxacin on the incidence of contamination of anterior chamber fluid postoperatively compared with placebo may be analysed in two ways. Firstly, growth either directly onto chocolate agar plate or broth subculture was combined to give an overall figure and showed no significant difference between the two treatment groups $\left(\chi^{2}=0, p=1 \cdot 0\right)$; similarly when growth onto direct plates and broth subcultures was considered separately there was still no significant difference between the two treatment groups $\left(\chi^{2}=0.9, p>0.5\right.$ for two degrees of freedom).

Speaker et al ${ }^{26}$ emphasised the role of external ocular tissues and their microbial flora in the prophylaxis and prevention of postoperative bacterial endophthalmitis. Using molecular epidemiological techniques they identified the patients' external bacterial flora as the source of the infecting organism in most of the cases of endophthalmitis examined. A variety of practices and procedures has long been directed at minimising the access of external bacterial flora to internal ocular tissues. The use of povidone iodine solution to prepare the conjunctiva for intraocular surgery has been shown to reduce the incidence of postoperative endophthalmitis. ${ }^{27}$ Although other studies have shown that preoperative antibiotics can reduce the bacterial counts from conjunctival swabs by up to $99.5 \%$, its efficacy in reducing the incidence of endophthalmitis has not been conclusively demonstrated. ${ }^{28}$ However Apt et $a l^{4}$ showed that povidone iodine applied to the ocular surface in conjunction with a preoperative course of topical antibiotic enhances its activity. In this study all eyes were aseptically prepared with $7 \cdot 5 \%$ povidone iodine solution and we isolated viable organisms in $24 \%$ of our samples of anterior chamber fluid. Moreover, we have shown no statistical difference in isolation rate of bacteria if pretreatment with the antibiotic norfloxacin is given. Although it would seem prudent to minimise or indeed eliminate the entry of bacteria into the eye during surgery it seems debatable whether this can be achieved by routine use of topical antibiotics preoperatively.

We should like to acknowledge the help of Mr Kevin Stannard in the Department of Ophthalmology and Dr A J Bint in the Department of Microbiology, Royal Victoria Infirmary, Newcastle upon Tyne for their technical assistance.
1 Sherwood DR, Rick WJ, Jacob JS, Hart RJ, Fairchild YL. Bacterial contamination of intra-ocular and extra-ocular fluids during extra-capsular cataract extraction. Eye 1989; 3 308.

2 Dickey JB, Thompson KD, Jay WM. Anterior chamber aspirate cultures after uncomplicated cataract surgery. Am $\mathcal{F}$ Ophthalmol 1991; 112: 278-82.

3 Whitney CR, Anderson RP, Allan Smith MA. Pre-operatively Whitney CR, Anderson RP, Allan Smith MA. Pre-operatively administered antibiotics. Their effect on bacter
the eyelids. Arch Ophthalmol 1972; 87: 155 .

4 Apt L, Isenberg SJ, Yoshimori R, Spieter A. Outpatient topical use of povidone-iodine in preparing the eye for surgery. Ophthalmology 1989; 96: 289-92.

5 Kattan HM, Flynn HW Jr, Pflugfelder SC, Robertson C, Forster RK. Nosocomial endophthalmitis survey. Curren incidence of infection after intraocular surgery. Ophthalmology 1991; 98: 227-38.

6 Stark WJ, Worthen DM, Holladay J, Bath PE, Jacobs ME, Murray GC, et al. The FDA report on intraocular lenses. Ophthalmology 1983; 90: 311-7.

7 Sen DK, Sarin GS, Saha K. Immunoglobulins in human aqueous humour. Br $\mathcal{F}$ Ophthalmol 1977; 61: 216

8 Modino BJ, Rao H. Complement levels in normal and inflamed aqueous humour. Invest Ophthalmol Vis Sci 1983; 24: 380.

9 Barza M, Doft B, Lynch E. Ocular penetration of ceftriaxone, ceftazidime and vancomycin after subconjunctival injection in humans. Arch Ophthalmol 1993: 111: 492-4.

10 Perlman MD. Prophylactic subconjunctival penicillin and streptomycin after cataract extraction. Arch Ophthalmo 1956; 55: 516-8.

11 Kolker AE, Freeman MI, Petit TA. Prophylactic antibiotics and postoperative endophthalmitis. Am f Ophthalmol 1967; 63: 434-9.

12 Beyer TL, Vogler G, Sharma D, O'Donnell FE. Posterior barrier effect of posterior lens capsule in exogenous bacterial endophthalmitis. An experimental primate study. Invest Ophthalmol Vis S ci 1984; 25: 108.

13 Beyer TL, O'Donnell FE, Goncalves V, Singh R. Role of the posterior capsule in the prevention of post-operative bacterial endophthalmitis. Experimental primate studies and clinical implication. Brf Ophthalmol 1985; 69: 841

14 Shockley RK, Jay WM, Fishman PH, Aziz MZ, Rissing JP. Effect of inoculum size on the induction of endophthalmitis in aphakic rabbit eyes. Acta Ophthalmol (Copenh) 1985 63: 35

15 Maylath FR, Leopold IH. Study of experimental intra-ocular infection. I. The recoverability of organisms inoculated into ocular tissues and fluids. II. The influence of antibiotics and cortisone alone and combined on intra-ocular growth of cortisone alone and combined on intra-ocular

16 Dilly PN, Holmes Sellors PJ. Bacterial adhesion to intra-ocular lenses. F Cataract Refract Surg 1989; 15: 317-20.

17 Griffiths PG, Elliott TSJ, McTaggart L. Adherence of Staphy lococcus epidermis to intra-ocular lenses. Br $\mathcal{F}$ Ophthalmo 1989; 73: 402-6.

18 Menikoff JA, Speaker MG, Manner M, Raskin EM. A casecontrol study of risk factors for post-operative endophthalmitis. Ophthalmology 1991; 98: 1761-8.

19 Heaven CJ, Mann PJ, Boase DL. Endophthalmitis following extra-capsular cataract surgery: a review of 32 cases. extra-capsular cataract surgery:

20 Puliafito CA, Baker AS, Haaf J, Foster CS. Infectious endophthalmitis. Ophthalmology 1982; 89: 921-9.

21 Driebe WT, Mandelbaum S, Forster RK, Schwartz LK, Culbertson WW. Pseudophakic endophthalmitis: diagnosis and management. Ophthalmology 1986; 93: 442-8.

22 Forster RK. Aetiology and diagnosis of bacterial postoperative endophthalmitis. Ophthalmology 1978; 85: 320-6.

23 Walker CB, Claoue CMP. Incidence of conjunctival colonisation by bacteria capable of causing post-operative endophthalmitis. F Roy Soc Med 1986; 79: 520-1.

24 Shungu DL. In vitro antibacterial activity of norfloxacin and other agents against ocular pathogens. Chemotherapy 1985 ; other age 112 .

25 Ooishi M, Oomomo A, Sakaue F, Tazawa H. Studies on NFLX levels in cul de sac and intra-ocular penetration of NFLX eye drops. Acta Soc Ophthalmol fpn 1987; 161.

26 Speaker MG, Milch FA, Shah MK, Eisner W, Kreiswirth BN. Role of external bacterial flora in pathogenesis of acute postoperative endophthalmitis. Ophthalmology 1991; 97 639-50.

27 Speaker MG, Menikoff JA. Prophylaxis of endophthalmitis with topical povidone-iodine. Ophthalmology 1991; 98: 1769-75.

28 Starr MB. Prophylactic antibiotics for ophthalmic surgery. Ophthalmology 1983; 27: 353-73. 